\title{
Functional Changes Induced by Short Term Caloric Restriction in Cardiac and Skeletal Muscle Mitochondria
}

Julian David C. Serna ${ }^{1}$, Camille C. Caldeira da Silva ${ }^{1}$ and Alicia J. Kowaltowski ${ }^{1}$

${ }^{1}$ Departamento de Bioquímica, Instituto de Química, Universidade de São

Paulo, São Paulo, Brazil. Correspondence: alicia@iq.usp.br

\begin{abstract}
Caloric restriction $(\mathrm{CR})$ is widely known to increase life span and resistance against different types of injuries in several organisms. We have previously shown that mitochondria from livers or brains of $C R$ animals exhibit higher calcium uptake rates and lower sensitivity to calcium-induced mitochondrial permeability transition (mPT), an event related to the resilient phenotype exhibited by these organs. Given the importance of calcium in metabolic control and cell homeostasis, we aimed here to uncover possible changes in mitochondrial calcium handling, redox balance and bioenergetics in cardiac and skeletal muscle mitochondria. Unexpectedly, we found that CR does not alter the susceptibility to $\mathrm{mPT}$ in muscle (cardiac or skeletal), nor calcium uptake rates. Despite the lack in changes in calcium transport properties, CR consistently decreased respiration in the presence of ATP synthesis in heart and soleus muscle. In heart, such changes were accompanied by a decrease in respiration in the absence of ATP synthesis, lower maximal respiratory rates and a reduced rate of hydrogen peroxide release. Hydrogen peroxide release was unaltered by $\mathrm{CR}$ in skeletal muscle. No changes were observed in inner membrane potentials and respiratory control ratios. Together, these results highlight the tissue-specific bioenergetic and ion transport effects induced by $\mathrm{CR}$, demonstrating that resilience against calcium-induced $\mathrm{mPT}$ is not present in all tissues.
\end{abstract}

Key words: Bioenergetics; Caloric Restriction; Mitochondrial Permeability Transition; Heart; Reactive Oxygen Species; Soleus Muscle. 


\section{Introduction}

Heart and skeletal muscle exhibit several detrimental changes during aging, and are key tissues in age-related dysfunctions (McCormick et al., 2018; Chiao \& Rabinovitch, 2015; López-Otín et al., 2013; de Melo et al., 2018). Both display a high dependence on aerobic metabolism for their performance, and remarkable metabolic plasticity, with adaptations to use different substrates, as well as to changes in oxygen and nutrient supply (Lesnefski, et al. 2017; Chouchani et al., 2014; Gillani et al., 2012). Since mitochondria are central organelles in metabolic plasticity, strategies to preserve mitochondrial function in these tissues are the focus of intense research (Lázár et.al., 2017).

A mitochondrial phenomenon associated with many age-related pathological conditions is the mitochondrial permeability transition (mPT), a sudden increase in inner mitochondrial membrane permeability (Hunter \& Haworth, 1979a; Haworth \& Hunter, 1979b, Haworth \& Hunter, 1979, reviewed by Chinopoulus, 2018; Vercesi et al., 2018). mPT results in loss of ion gradients and metabolite accumulation, hampering oxidative phosphorylation. Swelling and rupture of the outer mitochondrial membrane secondary to $\mathrm{mPT}$ may also promote cell death by necrosis or apoptosis, thus leading to tissue damage in a variety of pathological conditions (Lemasters et al., 2009; Figueira et al., 2013; Vercesi et al., 2018).

Calcium overaccumulation in mitochondria is the central trigger for $\mathrm{mPT}$, which is also stimulated by a high concentration of oxidants, protein thiol oxidation and missfolding, phosphate, and many other stimuli (Halestrap et al., 2015; Figueira et al., 2013; Vercesi et al., 2018). mPT induction is closely related to mitochondrial oxidant release; interventions that augment antioxidant defenses and/or decrease the rate of oxidant release are expected to decrease the probability of mPT (reviewed in Kowaltowski et al., 2001; Figueira et al., 2013; Vercesi et al., 2018). Susceptibility to MPT also increases with age in several tissues (Panel et al., 2018). The same is observed with conditions that promote unhealthy aging, such as high-fat diets, obesity and diabetes (Littlejohns et al., 2014; Castillo et al., 2019; Anderson et al., 2019). In contrast, caloric restriction $(\mathrm{CR})$, a dietetic intervention that involves a decrease in energy intake without malnutrition is well known to promote an increase in lifespan and 
improve healthspan, and protects against calcium-induced $\mathrm{MPT}$ in rodent livers and brains (Kristal et al., 1998; Amigo et al., 2017; Menezes-Filho et al., 2017). Short term CR also increases mitochondrial calcium retention capacity and uptake rates in these tissues (Amigo et al. 2017; Menezes et al. 2017). These data support the idea that $\mathrm{mPT}$ and mitochondrial $\mathrm{Ca}^{2+}$ transport are modulated by aging and diet.

Indeed, several studies demonstrate that CR decreases the rate of oxidant release by mitochondria, an important factor in $\mathrm{mPT}$ induction (Kowaltowski et al., 2001; Figueira et al., 2013; Vercesi et al., 2018). However, other papers demonstrate unaltered, decreased and even increased in oxidant release with dietary restriction (Walsh et al. 2014), so a prevention of oxidant formation does not seem to be a consistent finding in CR. Mitochondrial bioenergetics also has been shown to be modulated by $\mathrm{CR}$, preventing agerelated dysfunction of the electron transport chain (ETC) in heart and different types of skeletal muscle (Hofer et al, 2009; Lanza et al., 2012). However, calcium transport properties of heart and skeletal muscle mitochondria from CR animals have not been explored within the current framework. Here, we aimed to uncover possible alterations in mitochondrial calcium transport, $\mathrm{mPT}$, bioenergetics and $\mathrm{H}_{2} \mathrm{O}_{2}$ release induced by $\mathrm{CR}$, in heart and soleus muscle. Interestingly, we found that the effects of $\mathrm{CR}$ in brain and liver are not applicable to skeletal tissues, indicating that CR-induced modulation of mitochondrial $\mathrm{Ca}^{2+}$ transport is tissue-specific. 


\section{Experimental Procedures}

\section{Animal care and caloric restriction}

Experiments were approved by the local committee for animal care and use and followed NIH guidelines. Male Sprague-Dawley (NTac:SD) rats were used, bred and lodged at the Biotério de Produção e Experimentação da Faculdade de Ciências Farmacêuticas e Instituto de Química. Animals were lodged in plastic ventilated cages (49 cm x $34 \mathrm{~cm} \times 16 \mathrm{~cm}$ ), 2 animals per cage, under specific pathogen free conditions, at constant temperature $\left(22 \pm 2^{\circ} \mathrm{C}\right)$ and relative air humidity $(50 \pm 10 \%)$. They were exposed to a photoperiod of $12 \mathrm{~h}$ light / $12 \mathrm{~h}$ dark, with the light period beginning at 6:00. Until 12 week (adults), the animals were provided with the standard AIM93G diet (prepared by Rhoster). After that, animals were randomly divided in two groups. Following a brief period of adaptation ( 2 days), the daily food consumption of the CR group was established as $60 \%$ of the ad libitum feeding quantity. CR animals were then provided with supplemented AIM93M chow (Rhoster) to induce $40 \%$ CR without changes in vitamin and mineral levels (Cerqueira and Kowaltowski, 2010). Over the next months, food consumption was adjusted based on AL daily food consumption. Water consumption was maintained ad libitum.

\section{Euthanasia}

Animals were fasted before each experiment for 10-12 $\mathrm{h}$, beginning at 19:00. Before euthanasia, they were deeply anesthetized $\left(1 \mathrm{~mL} \cdot \mathrm{Kg}^{-1}\right.$ ketamine, $0.6 \mathrm{~mL} \cdot \mathrm{Kg}^{-1}$ xylazine and $0.5 \mathrm{~mL} \cdot \mathrm{Kg}^{-1}$ acepromazine, subcutaneously). Animals were then submitted to cardiac puncture and the diaphragm was cut. Four animals were employed per group.

\section{Mitochondrial isolation}

Heart mitochondria were isolated as described by Gostimskaya and Galkin (2010) with a few modifications. All steps were performed at $4^{\circ} \mathrm{C}$. After 
washing in PBS supplemented with $10 \mathrm{mM}$ EDTA, connective tissues were rapidly removed. The heart was chopped into small segments and then incubated in washing buffer (0.3 M sucrose, $10 \mathrm{mM}$ HEPES, $2 \mathrm{mM}$ EGTA, 1 $\mathrm{mM}$ EDTA, $\mathrm{pH}=7.2$ ) plus $0.125 \mathrm{mg} \cdot \mathrm{mL}^{-1}$ trypsin during $10 \mathrm{~min}$. The mixture was homogenized in a tissue grinder (at least three strokes) and then incubated during 5 additional minutes in an additional amount of washing buffer, again supplemented with trypsin. After that, three additional strokes were performed to complete the homogenization step. The suspension was diluted with $0.2 \%$ BSA to inactivate trypsin. The mitochondrially-enriched fraction was prepared through differential centrifugation. The suspension was initially centrifuged at $600 \mathrm{~g}$ during $15 \mathrm{~min}$, and the resultant supernatant was then centrifuged at $8500 \mathrm{~g}$. The pellet was resuspended in $10 \mathrm{~mL}$ of isolation buffer, and again centrifuged at $8500 \mathrm{~g}$ for 10 minutes. The pellet was finally resuspended, including the fluffy layer (to avoid eliminating mitochondria differentially between samples), in a minimum amount of isolation buffer. Protein concentration was determined using the Bradford Method.

Skeletal muscle mitochondria were isolated, with some modifications, as previously described by Frezza et al. 2007). All procedures were performed at $4^{\circ} \mathrm{C}$. The soleus muscle of each hind limb was collected and washed in PBS supplemented with 10 mM EDTA. After connective tissue removal, the muscles were chopped in small pieces and then incubated in muscle isolation buffer 1 (67 mM sucrose, $50 \mathrm{mM} \mathrm{KCl,} 1 \mathrm{mM}$ EDTA, and $0.125 \mathrm{mg} \cdot \mathrm{mL}^{-1}$ trypsin; $\mathrm{pH}=$ 7.4) during 10 minutes. The mixture was homogenized (3-4 strokes) and then incubated during $5 \mathrm{~min}$ in an additional amount of buffer, in the presence of $0.125 \mathrm{mg} \cdot \mathrm{mL}^{-1}$ trypsin. The suspension was processed again in the tissue grinder (3 strokes) and then diluted with isolation buffer plus $0.2 \%$ BSA (fatty acid free). The suspension was centrifuged at $800 \mathrm{~g}$ during $15 \mathrm{~min}$, and the resulting supernatant was then centrifuged at $8500 \mathrm{~g}$ for $10 \mathrm{~min}$. The pellet was resuspended in $10 \mathrm{~mL}$ of isolation buffer, and centrifuged again at $8500 \mathrm{~g}$. Finally, the pellet was resuspended in isolation buffer (including the fluffy layer). Protein concentration was measured through the Bradford Method. 
$\mathrm{Ca}^{2+}$ uptake assays

$500 \mu \mathrm{g}$ of the mitochondrially-enriched fraction (derived from heart or soleus muscle) were incubated in $2 \mathrm{~mL}$ of experimental buffer (125 mM sucrose, $65 \mathrm{mM} \mathrm{KCl}, 10 \mathrm{mM}$ Hepes, $2 \mathrm{mM}$ phosphate, $2 \mathrm{mM} \mathrm{MgCl}$ and $0.2 \%$ bovine serum albumin, adjusted to $\mathrm{pH} 7.2$ with $\mathrm{KOH}$ ), plus $0.1 \mu \mathrm{M}$ Calcium Green $5 \mathrm{~N}$ and $1 \mathrm{mM}$ succinate, in the presence of $2 \mu \mathrm{M}$ rotenone. Calcium Green 5N fluorescence was measured with a F4500 Hitachi Fluorimeter at excitation and emission wavelengths of $506 \mathrm{~nm}$ and $532 \mathrm{~nm}$, at $37^{\circ} \mathrm{C}$, under constant stirring. Several additions of $10 \mu \mathrm{M} \mathrm{Ca}^{2+}$, with 3 minute intervals, were made until mPT induction (Amigo et al., 2017; Menezes-Filho et al., 2017).

The relationship between Calcium Green $5 \mathrm{~N}$ fluorescence $(\mathrm{F})$ and $\left[\mathrm{Ca}^{2+}\right]$ concentrations was established using the equation $\left[\mathrm{Ca}^{2+}\right]=\mathrm{K}_{d} \cdot\left(\mathrm{F}-\mathrm{F}_{\min }\right) /\left(\mathrm{F}_{\max }-\mathrm{F}\right)$. The $K_{d}$ value was empirically determined as the value at which the change in fluorescence $(\Delta \mathrm{F})$ after each calcium addition is equivalent to a $10 \mu \mathrm{M}$ change in calcium concentration $\left(\Delta\left[\mathrm{Ca}^{2+}\right]\right)$. The maximal $\left(F_{\max }\right)$ and minimal $\left(F_{\min }\right)$ fluorescence were determined at the end of each trace using $100 \mu \mathrm{L}$ of $100 \mathrm{mM}$ $\mathrm{Ca}^{2+}$ and $100 \mathrm{mM}$ EGTA solutions, respectively. The calcium retention capacity was determined as the total amount of calcium $\mathrm{Ca}^{2+}$ taken up by mitochondria until the induction of $\mathrm{mPT}\left(\mathrm{nmol} \mathrm{Ca} \mathrm{Ca}^{2+} \cdot \mathrm{mg}\right.$ protein $\left.^{-1}\right)$. Calcium uptake rates were determined as the slope of the linear portion $\left(\mathrm{nmol} \mathrm{Ca}{ }^{2+} \cdot \mathrm{mg} \mathrm{protein}^{-1} \cdot \mathrm{s}^{-1}\right)$ at the beginning of the first calcium addition. An exponential decay fit (first order kinetics) was used to calculate the minimum calcium concentration achieved in the medium, or the affinity of mitochondria for $\mathrm{Ca}^{2+}$, a concentration under which calcium is not taken up by mitochondria.

\section{Mitochondrial oxygen consumption}

Oxygen consumption was assessed using high-resolution Oroboros oxygraph. Heart mitochondria $(75 \mu \mathrm{g})$ or $150 \mu \mathrm{g}$ of the soleus muscle mitochondrial fraction were suspended in $2 \mathrm{~mL}$ of the same experimental buffer used for calcium uptake assays. Mitochondria were incubated with $1 \mathrm{mM}$ succinate in the presence of $1 \mu \mathrm{M}$ rotenone, under constant stirring at $37^{\circ} \mathrm{C}$. 
ADP (2 mM) was used to induce State 3. State 4 and maximal respiration (state 3u, uncoupled) were induced with $1 \mu \mathrm{M}$ oligomycin (muscle and heart mitochondria) and CCCP (1.25 $\mu \mathrm{M}$ or $2 \mu \mathrm{M}$ for heart or soleus mitochondria), respectively. Respiratory control ratios were determined as State 3 divided by State 4.

Inner mitochondrial membrane potential measurements

Mitochondrial membrane potentials $(\Delta \Psi)$ were estimated through changes in the fluorescence (quenching mode) of the safranin $\mathrm{O}$ dye (Akerman \& Wikström, 1976). $75 \mu \mathrm{g}$ of heart mitochondria (or $100 \mu \mathrm{g}$ of soleus muscle mitochondria) were incubated in $2 \mathrm{~mL}$ experimental buffer in the presence of $5 \mu \mathrm{M}$ Safranin $\mathrm{O}, 1 \mathrm{mM}$ succinate and $1 \mu \mathrm{M}$ rotenone (State 2), $\mathrm{pH}=7.4$, adjusted with $\mathrm{KOH}$. The $\Delta \Psi$ values different respiratory states were assessed as described above. Fluorescence was followed in an F2500 Hitachi Fluorimeter at excitation and emission wavelengths of $485 \mathrm{~nm}$ and $586 \mathrm{~nm}$, respectively, under constant stirring, at $37^{\circ} \mathrm{C}$. The dye is accumulated in the mitochondrial matrix in a $\Delta \Psi$-dependent fashion; membrane depolarization leads to an increase in net fluorescence. A calibration curve was employed to establish a relationship between $\Delta \Psi$ and fluorescence (Kowaltowski et al., 2002). $\Delta \Psi$ was clamped at different values through changes in extramitochondrial $\mathrm{K}^{+}$concentrations, in an initially $\mathrm{K}^{+}$-free experimental media.

Hydrogen peroxide release from isolated mitochondria

Mitochondrial $\mathrm{H}_{2} \mathrm{O}_{2}$ release was followed through the oxidation of Amplex Red $(25 \mu \mathrm{M})$, a reaction catalyzed by horseradish peroxidase $(5 \mathrm{U} / \mathrm{mL}$; HRP; Zhou et al., 1997). $75 \mu \mathrm{g}$ of heart mitochondria or $100 \mu \mathrm{g}$ soleus muscle mitochondria were added to $2 \mathrm{~mL}$ of experimental media in the presence of 1 $\mathrm{mM}$ succinate and $1 \mu \mathrm{M}$ rotenone under constant stirring, at $37^{\circ} \mathrm{C}$. The oxidation of Amplex Red generates a fluorescent compound (resorufin), which was detected with a F2500 Hitachi Fluorimeter at a excitation and emission 
wavelength of $563 \mathrm{~nm}$ and $587 \mathrm{~nm}$, respectively. A calibration curve, used to establish a relationship between resorufin fluorescence and $\mathrm{H}_{2} \mathrm{O}_{2}$ concentration, was constructed under the same experimental conditions (in the absence of mitochondria), by sequentially adding known quantities of $\mathrm{H}_{2} \mathrm{O}_{2}$.

Statistical analysis

Results are presented as means \pm SEM and were analyzed using GraphPad Prism Software 4.0. Data were compared using t-tests. 


\section{Results}

CR does not change heart mitochondrial calcium transport properties

We have previously found that $\mathrm{CR}$ increases $\mathrm{Ca}^{2+}$ uptake rates and resistance against calcium-induced $\mathrm{mPT}$ in the liver and brain (Amigo et al., 2017; Menezes-Filho et al., 2017). This lead us to investigate possible changes in heart mitochondrial calcium handling promoted by CR (Fig. 1). We isolated a mitochondrial fraction containing both subsarcolemmal and intermyofibrillar populations of these organelles (Palmer et al., 1977). These mitochondria were incubated in the presence of $\mathrm{Ca}^{2+}$ Green $5 \mathrm{~N}$, which fluoresces upon calcium binding but is not membrane-permeable, thus allowing us to detect changes in the calcium concentrations of the extramitochondrial compartment. Fig. 1A shows a typical calcium uptake trace of mitochondria obtained from hearts of ad libitum ( $\mathrm{AL}$, blue trace) or CR (red trace) rats. After each $10 \mu \mathrm{M}$ addition of calcium, marked by an arrow, and acute increases in $\left[\mathrm{Ca}^{2+}\right]$ promoted by the addition, a gradual decrease in extra-mitochondrial calcium concentration is observed, indicative of uptake of the ion by mitochondria. Each trace finished after induction of $\mathrm{mPT}$, marked by a sudden increase in extramitochondrial calcium (release of stored calcium). No differences in $\mathrm{Ca}^{2+}$ retention capacity were noted between the $\mathrm{AL}$ and $\mathrm{CR}$ groups (Fig. 1B shows quantified comparisons).

We also investigated possible changes in the kinetics of calcium clearance by mitochondria. Fig. 1C shows an initial calcium uptake rate trace, quantified in Fig. 1D. Under the experimental conditions employed, we were not able to detect any diet-induced changes in the calcium uptake rate. Finally, the affinity of mitochondria for $\mathrm{Ca}^{2+}\left(\left[\mathrm{Ca}^{2+}\right]\right.$ in the media after uptake stabilized) was equal in $\mathrm{CR}$ and $\mathrm{AL}$ groups (Fig. 1E). Overall, heart mitochondrial $\mathrm{Ca}^{2+}$ uptake properties and their modulation by CR differ significantly in heart from brain or liver (Amigo et al., 2017; Menezes-Filho et al., 2017), suggesting that the effects of $\mathrm{CR}$ on mitochondrial $\mathrm{Ca}^{2+}$ uptake are tissue-specific. 
CR alters mitochondrial oxygen consumption and redox state without changes in coupling or the inner membrane potential

The ability of CR to preserve or increase bioenergetic fitness in heart mitochondria over time is debated (Walsh et al. 2014). We investigated possible changes in mitochondrial oxygen consumption using an Oroboros high resolution respirometer (Fig. 2). When ADP was added to induce oxidative phosphorylation (state 3 respiration), CR mitochondria displayed lower respiratory rates (Fig. 2A). The same was observed when ATP synthase was inhibited by oligomycin (state 4 respiration) or maximized by the uncoupler CCCP (maximal respiration), demonstrating that CR limits electron transport rates in heart mitochondria. Interestingly, these changes were not accompanied by any alteration in respiratory control ratios (Fig. 2B), which determine coupling between respiration and ATP synthesis, measured as State 3/State 4. Indeed, calibrated inner mitochondrial membrane potentials ( $\Delta \Psi$, Akerman, 1976; Kowaltwski et al., 2002) were identical in AL and CR mitochondria (Fig. 2C). Since $\Delta \Psi$ is the driving force for $\mathrm{Ca}^{2+}$ accumulation, this lack of change may explain the equal $\mathrm{Ca}^{2+}$ uptake rates observed in Fig. 1.

Changes in oxygen consumption or $\Delta \Psi$ are often associated with altered mitochondrial oxidant release (Korshunov et al., 1997; Caldeira da Silva et al. 2008; Tahara et al., 2009). We consequently measured possible changes in $\mathrm{H}_{2} \mathrm{O}_{2}$ release by mitochondria using Amplex Red and horseradish peroxidase (Zhou et al., 1997). CR promoted a substantial decrease in $\mathrm{H}_{2} \mathrm{O}_{2}$ release by heart mitochondria (Fig. 2D).

CR does not change soleus muscle mitochondrial calcium transport properties

We tested the ability of CR to promote changes in calcium handling in skeletal muscle mitochondria. Mitochondria were isolated from the soleus muscle, enriched in type I fibers and with high dependence on aerobic metabolism (Soukup et al., 2002), using a preparation containing intermyofibrillar and subsarcolemmal populations (Kayar et al., 1988). Fig. 3A depicts a representative calcium uptake trace, quantified in Fig. 3B. A 
remarkably higher (around $50 \%$ ) calcium retention capacity was seen in soleus mitochondria when compared to heart mitochondria, but CR did not promote changes in maximal $\mathrm{Ca}^{2+}$ uptake and the sensibility to calcium-induced $\mathrm{mPT}$. Calcium uptake rates in soleus mitochondria (Fig. 3C, 3D) were also unchanged by $\mathrm{CR}$, but around $70 \%$ higher than for heart mitochondria. Finally, the affinity for $\mathrm{Ca}^{2+}$ was unchanged by $\mathrm{CR}$, but higher in skeletal muscle than in heart (Fig. 3E).

CR decreases mitochondrial state 3 oxygen consumption without changes in coupling, membrane potentials or $\mathrm{H}_{2} \mathrm{O}_{2}$

As previously observed in heart mitochondria, CR promotes a decrease in skeletal muscle respiration under state 3 conditions (Fig. 4A). No changes in state 4 and maximal respiration were observed as a result of the CR diet. Mitochondrial respiratory control ratios in muscle were also unchanged as result of the dietary intervention, Fig. $4 \mathrm{~B}$, as were $\Delta \Psi$ and $\mathrm{H}_{2} \mathrm{O}_{2}$ release, Fig. $4 \mathrm{C}$ and 4D. 


\section{Discussion}

We have previously found that $\mathrm{CR}$ increased both calcium uptake rates and maximal uptake capacity in isolated brain and liver mitochondria (Amigo et al., 2017; Menezes et al., 2017). Given the central role of both mitochondria and calcium ions in the regulation of energy metabolism, we find the modulation of $\mathrm{Ca}^{2+}$ transport in mitochondria by a dietary intervention important. As a result, we investigated if this change was observed in muscle tissues, in which rich $\mathrm{Ca}^{2+}$-induced metabolic changes are also observed. Surprisingly, neither tissue displayed any change in mitochondrial $\mathrm{Ca}^{2+}$ transport properties with the dietary intervention, although some bioenergetic changes were observed, namely a decrease in phosphorylating oxygen consumption rates and, in heart, decreased $\mathrm{H}_{2} \mathrm{O}_{2}$ release.

It should be noted that isolation of mitochondria from the tissue can change mitochondrial morphology and distribution in the cell (Kuznetsov et al. 2008), factors affecting mitochondrial $\mathrm{Ca}^{2+}$ uptake properties (Kowaltowski et al. 2019; Favaro et al. 2019). Thus, our experimental setup does not eliminate the possibility of in vivo differences. However, changes in isolated mitochondrial $\mathrm{Ca}^{2+}$ transport induced by $\mathrm{CR}$ and fasting were measured in isolated mitochondrial from brain and liver previously, showing that these can be independent of in vivo morphology (Amigo et al., 2017; Menezes-Filho et al., 2017). This suggests that changes seen in mitochondrial $\mathrm{Ca}^{2+}$ transport promoted by $\mathrm{CR}$ are indeed tissue-specific.

A prior publication (Hofer et al., 2009) explored the effects of CR on mitochondrial calcium transport and $\mathrm{mPT}$ in the heart. This work differed from ours in the sense that the diet adopted was the NIH CR protocol, which involves supplementation with vitamins but not minerals in the CR group, which can significantly change mitochondrial metabolic properties (Cerqueira and Kowaltowski, 2010). Furthermore, the paper compared different fractions of mitochondria isolated from animals under distinct feeding states: fasted $C R$ compared against non-fasted AL rats (Hofer et al., 2009). Recent work from our group in liver indicates that substantial remodeling of mitochondrial function occurs with a few hours of fasting (Menezes-Filho et al., 2019), and we do not 
know if these changes could also be present in heart. Nonetheless, the overall results obtained by both our group and theirs are consistent in the sense that only small or no changes in heart mitochondrial $\mathrm{Ca}^{2+}$ transport are promoted by CR.

In heart, mitochondrial hydrogen peroxide release rates were decreased by $\mathrm{CR}$, while in soleus muscle mitochondria no such changes were detected. The available literature regarding redox balance and CR in heart mitochondria is mixed, with some works reporting decreased or even unaltered reactive oxygen species release in response to CR (Walsh et al. 2014). The same inconsistent results have been reported in the literature for skeletal muscle (Walsh et al. 2014). To to our knowledge, no prior reports were available related to the effects of $\mathrm{CR}$ on soleus muscle redox balance. However, our data contrast with work that measured $\mathrm{H}_{2} \mathrm{O}_{2}$ release in Male Fischer 344 Brown $\mathrm{x}$ Norway hybrid (F344xBN F1) rats (Hofer et al., 2009) and observed a decrease in peroxide release promoted by CR. Notably, these changes were significant only at 18 and 29 months of age, a much more advanced time point than analyzed by us. This suggests changes in $\mathrm{H}_{2} \mathrm{O}_{2}$ release promoted by $\mathrm{CR}$ in muscle may be a consequence of different aging rates with $\mathrm{CR}$, rather than an early effect of the intervention.

Both in heart and skeletal muscle, we measured moderate decreases in respiratory rates under phosphorylating conditions. Mixed results have also been reported previously for $\mathrm{CR}$ effects on heart mitochondrial respiration (Desai 1996; Judge et al., 2004; Hofer et al 2009; Lanza et al 2012; Ruetenik et al. 2015). The predominant view includes non-modified or even increased respiratory rates induced by this diet, which makes our finding surprising. Many of these works, however, employed different substrates, different kinds of mitochondrial preparations, other species or strains, other forms of dietary limitation (Cerqueira and Kowaltowski, 2010), as well as other treatment durations. Indeed, bioenergetic changes induced by CR in soleus muscle were not available to date, to our knowledge. 


\section{Conclusions}

We measured mitochondrial respiration, inner membrane potentials and $\mathrm{H}_{2} \mathrm{O}_{2}$ in heart and soleus muscle, adding upon data in the literature and demonstrating that many tissue, substrate and diet-specific changes in bioenergetics and oxidant production exist. We also measured mitochondrial $\mathrm{Ca}^{2+}$ uptake, including maximal uptake capacity, $\mathrm{Ca}^{2+}$ uptake rates, and affinity. Interestingly, we found that these were unchanged by $\mathrm{CR}$, a result that contrasts sharply with brain and liver, in which CR strongly enhances $\mathrm{Ca}^{2+}$ uptake in mitochondria. These results highlight the strong tissue-specificity of mitochondrial effects of CR. 


\section{Declarations}

Funding: Supported by the Fundação de Amparo à Pesquisa do Estado de São Paulo (FAPESP) grant number 2016/18633-8, Conselho Nacional de Pesquisa e Desenvolvimento (CNPq) grant number 440436/2014, Coordenação de Aperfeiçoamento de Pessoal de Nível Superior (CAPES) finance code 001, and the Centro de Pesquisa, Inovação e Difusão de Processos Redox em Biomedicina - CEPID Redoxoma, grant 2013/07937-8. JDCS is supported by a FAPESP fellowship.

Conflicts of interest: none

Availability of data and material: raw data are fully available upon request

Code availability: none

Authors' contributions: All authors participated in experimental design, data analysis, reading and approval of the final manuscript. JDCS and CCCS conducted experiments. 


\section{References}

Akerman KEO, Wikstrom MKF (1976) Safranine as a probe of mitochondrialmembrane potential. FEBS Lett 68:191-197

Amigo I, Menezes-Filho SL, Luevano-Martinez LA, Chausse B, Kowaltowski AJ (2017) Caloric restriction increases brain mitochondrial calcium retention capacity and protects against excitotoxicity. Aging Cell 16:73-81

Anderson EJ, Rodriguez E, Anderson CA, Thayne K, Chitwood WR, Kypson AP (2011) Increased propensity for cell death in diabetic human heart is mediated by mitochondrial-dependent pathways. Am J Physiol - Heart Circ Physiol 300:118-124

Caldeira da Silva CC, Cerqueira FM, Barbosa LF, Medeiros MHG, Kowaltowski AJ (2008). Mild mitochondrial uncoupling in mice affects energy metabolism, redox balance and longevity. Aging Cell 7:552-560

Castillo EC, Morales JA, Chapoy-Villanueva H, Silva-Platas C, Treviño-Saldaña N, Guerrero-Beltrán CE, Bernal-Ramírez J, Torres-Quintanilla A, García N, Youker K, Torre-Amione G, García-Rivas G (2019) Mitochondrial hyperacetylation in the failing hearts of obese patients mediated partly by a reduction in SIRT3: The involvement of the mitochondrial permeability transition pore. Cell Physiol Biochemi 253:465-479

Cerqueira FM, Kowaltowski AJ (2010) Commonly adopted caloric restriction protocols often involve malnutrition. Ageing Res Rev 9:424-30

Chiao YA, Rabinovitch PS (2015) The aging heart. Cold Spring Harbor Persp Med 5:1-15

Chinopoulos C (2018) Mitochondrial permeability transition pore: Back to the drawing board. Neuroch Int 117:49-54

Chouchani ET, Pell VR, Gaude E, Aksentijević D, Sundier SY, Robb EL, Murphy MP (2014) Ischaemic accumulation of succinate controls reperfusion injury through mitochondrial ROS. Nature 515:431-435

de Mello AH, Costa AB, Engel JDG, Rezin GT (2018) Mitochondrial dysfunction in obesity. Life Sci 192:26-32

Desai VG, Weindruch R, Hart RW, Feuers RJ (1996) Influences of age and dietary restriction on gastrocnemius electron transport system activities in mice. Arch Biochem Biophy 333:145-151

Favaro G, Romanello V, Varanita T, Desbats AM, Morbidoni V, Tezze C, Sandri M (2019) DRP1-mediated mitochondrial shape controls calcium homeostasis and muscle mass. Nature Commun 10:2576 
Figueira TR, Barros MH, Camargo AA, Castilho RF, Ferreira JC, Kowaltowski AJ, Sluse FE, Souza-Pinto NC, Vercesi AE (2013) Mitochondria as a source of reactive oxygen and nitrogen species: from molecular mechanisms to human health. Antioxid Redox Signal 18:2029-2074

Frezza C, Cipolat S, Scorrano L (2007) Organelle isolation: Functional mitochondria from mouse liver, muscle and cultured fibroblasts. Nature Prot 2:287-295

Gillani S, Cao J, Suzuki T, Hak DJ (2012) The effect of ischemia reperfusion injury on skeletal muscle. Injury 43:670-675

Gostimskaya I, Galkin A (2010) Preparation of highly coupled rat heart mitochondria. J Vis Exp 23:2202

Halestrap AP, Richardson AP (2015) The mitochondrial permeability transition: A current perspective on its identity and role in ischemia/reperfusion injury. J Mol Cell Cardiol 78:129-141

Haworth RA, Hunter DR (1979) The $\mathrm{Ca}^{2+}$-induced membrane transition in mitochondria. II. Nature of the $\mathrm{Ca}^{2+}$ trigger site. Arch Biochem Biophys 195:460-467

Hofer T, Servais S, Seo AY, Marzetti E, Hiona A, Upadhyay SJ, Leeuwenburgh C (2009) Bioenergetics and permeability transition pore opening in heart subsarcolemmal and interfibrillar mitochondria: Effects of aging and lifelong calorie restriction. Mech Ageing Devel 130:297-307

Hunter DR, Haworth RA (1979a) The $\mathrm{Ca}^{2+}$-induced membrane transition in mitochondria: I. The protective mechanisms. Arch Biochem Biophys 195:468-477

Hunter DR, Haworth RA (1979b) The $\mathrm{Ca}^{2+}$-induced membrane transition in mitochondria. III. Transitional $\mathrm{Ca}^{2+}$ release. Arch Biochem Biophys 195:468-477

Judge S, Judge A, Grune T, Leeuwenburgh C (2004). Short-term CR decreases cardiac mitochondrial oxidant production but increases carbonyl content. Am J Physiol Reg Int Comp Physiol 286:254-259

Kayar SR, Hoppeler H, Mermod L, Weibel ER (1988) Mitochondrial size and shape in equine skeletal muscle: A three-dimensional reconstruction study. Anat Rec 222:333-339

Korshunov SS, Skulachev VP, Starkov AA (1997). High protonic potential actuates a mechanism of production of reactive oxygen species in mitochondria. FEBS Lett 416:15-18

Kowaltowski AJ, Castilho RF, Vercesi EA (2001) Mitochondrial permeability transition and oxidative stress. FEBS Lett 495:12-15 
Kowaltowski AJ, Cosso RG, Campos CB, Fiskum G (2002) Effect of Bcl-2 overexpression on mitochondrial structure and function. $J$ Biol Chem $277: 42802-42807$

Kowaltowski AJ, Menezes-Filho SL, Assali EA, Gonçalves IG, Cabral-Costa J V, Abreu P, Shirihai OS (2019) Mitochondrial morphology regulates organellar $\mathrm{Ca}^{2+}$ uptake and changes cellular $\mathrm{Ca}^{2+}$ homeostasis. FASEB J $33: 13176-13188$

Kristal BS, Yu BP (1998) Dietary restriction augments protection against induction of the mitochondrial permeability transition. Free Rad Biol Med 24:1269-1277

Kuznetsov AV, Veksler V, Gellerich FN, Saks V, Margreiter R, Kunz WS (2008). Analysis of mitochondrial function in situ in permeabilized muscle fibers, tissues and cells. Nature Prot 3:965-976

Lanza IR, Zabielski P, Klaus KA, Morse DM, Heppelmann CJ, Bergen HR, Nair, KS (2012) Chronic caloric restriction preserves mitochondrial function in senescence without increasing mitochondrial biogenesis. Cell Metab 16:777-788

Lázár E, Sadek HA, Bergmann O (2017) Cardiomyocyte renewal in the human heart: Insights from the fall-out. Eur Heart J, 38:2333-2339

Lemasters JJ, Theruvath TP, Zhong Z, Nieminen AL (2009) Mitochondrial calcium and the permeability transition in cell death. Bioch Biophys Acta Bioenerg 1787:1395-1401

Lesnefsky EJ, Chen Q, Tandler B, Hoppel CL (2017) Mitochondrial dysfunction and myocardial ischemia-reperfusion: implications for novel therapies. Ann Rev Pharm Tox 57:535-565

Littlejohns B, Pasdois P, Duggan S, Bond AR, Heesom K, Jackson CL, Suleiman MS (2014) Hearts from mice fed a non-obesogenic high-fat diet exhibit changes in their oxidative state, calcium and mitochondria in parallel with increased susceptibility to reperfusion injury. PLoS ONE 9:e100579

López-Otín C, Blasco MA, Partridge L, Serrano M, Kroemer G. (2013) The hallmarks of aging. Cell 153:1194

McCormick R, Vasilaki A (2018) Age-related changes in skeletal muscle: changes to life-style as a therapy. Biogerontology 19:519-536

Menezes-Filho SL, Amigo I, Prado FM, Ferreira NC, Koike MK, Pinto IFD, Kowaltowski AJ (2017) Caloric restriction protects livers from ischemia/reperfusion damage by preventing $\mathrm{Ca}^{2+}$-induced mitochondrial permeability transition. Free Rad Biol Med 110:219-227 
Menezes-Filho SL, Amigo I, Luévano-Martínez LA, Kowaltowski AJ (2019) Fasting promotes functional changes in liver mitochondria. Biochim Biophys Acta Bioenerg. 1860:129-135

Palmer W, Tandler B, Hoppel CL (1977) Biochemical interfibrillar muscle. J Biol Chem 236:8731-8739

Panel M, Ghaleh B, Morin D (2018) Mitochondria and aging: A role for the mitochondrial transition pore? Aging Cell 17:1-15

Ruetenik A, Barrientos A (2015) Dietary restriction, mitochondrial function and aging: From yeast to humans. Biochim Biophys Acta - Bioenerg 1847:1434-1447

Soukup T, Zachařová G, Smerdu V (2002) Fibre type composition of soleus and extensor digitorum longus muscles in normal female inbred Lewis rats. Acta Histoch 104:399-405

Tahara EB, Navarete FD, Kowaltowski AJ (2009) Tissue-, substrate-, and sitespecific characteristics of mitochondrial reactive oxygen species generation. Free Radic Biol Med 46:1283-1297

Vercesi AE, Castilho RF, Kowaltowski AJ, de Oliveira HCF, de Souza-Pinto NC, Figueira TR, Busanello ENB (2018) Mitochondrial calcium transport and the redox nature of the calcium-induced membrane permeability transition. Free Radic Biol Med. 2129:1-24

Walsh ME, Shi Y, Van Remmen H (2014) The effects of dietary restriction on oxidative stress in rodents. Free Rad Biol Med 66:88-99

Zhou M, Diwu Z, Panchuk-Voloshina N, Haugland RP (1997) A stable nonfluorescent derivative of resorufin for the fluorometric determination of trace hydrogen peroxide: Applications in detecting the activity of phagocyte NADPH oxidase and other oxidases. Anal Bioch 253:162-168 


\section{Figure Legends}

Figure 1. CR does not change heart mitochondrial $\mathrm{Ca}^{2+}$ retention capacity and uptake rate. $500 \mu \mathrm{g}$ of total mitochondrial protein were incubated in $2 \mathrm{~mL}$ media, as described in the methodology. A. Representative $\mathrm{Ca}^{2+}$ uptake traces of samples derived from $\mathrm{AL}$ (blue) or $\mathrm{CR}$ (red) animals; each arrow represents a $10 \mu \mathrm{M}$ calcium addition. B. Quantification of maximal $\mathrm{Ca}^{2+}$ retention capacity derived from graphs such as shown in Panel A. C. Representative mitochondrial $\mathrm{Ca}^{2+}$ uptake trace after the first $\mathrm{Ca}^{2+}$ addition. D. Quantification of initial mitochondrial $\mathrm{Ca}^{2+}$ uptake rates derived from plots such as shown in panel $\mathrm{C}$. E. Data such as from Panel A were fitted with a first order exponential decay to calculate the minimum $\left[\mathrm{Ca}^{2+}\right]$ reached in the medium, or the affinity of these mitochondria for $\mathrm{Ca}^{2+}$. $\mathrm{ns}=$ non-significant.

Figure 2. $\mathrm{CR}$ modulates heart mitochondrial oxygen consumption and $\mathrm{H}_{2} \mathrm{O}_{2}$ release without changes in coupling or inner membrane potentials. Mitochondrial oxygen consumption, membrane potentials $(\Delta \Psi)$ and peroxide release were measured as described in the methodology. Blue or red bars and points represent data obtained from AL or CR animals, respectively. A. Oxygen consumption rates were measured in mitochondria incubated, successively, in the presence of succinate and rotenone plus ADP (State 3), oligomycin (State 4) and CCCP (Maximal). B. Respiratory control ratios (State 3/State 4). C. Membrane potentials, calibrated in $\mathrm{mV}$. D. Hydrogen peroxide release normalized to average AL fluorescence. ${ }^{*} p<0.05$ versus $A L$. ns $=$ nonsignificant, ${ }^{*}=p<0.05$.

Figure 3. $\mathrm{CR}$ does not change soleus muscle mitochondrial $\mathrm{Ca}^{2+}$ retention capacity and uptake rate. $500 \mu \mathrm{g}$ of total mitochondrial protein were incubated in $2 \mathrm{~mL}$ media, as described in the Experimental section. A. Representative $\mathrm{Ca}^{2+}$ uptake traces of samples derived from AL (blue) or CR (red) animals; each arrow represents a $10 \mu \mathrm{M}$ calcium addition. B. Quantification of maximal $\mathrm{Ca}^{2+}$ retention capacity derived from graphs such as shown in Panel A. C. Representative mitochondrial $\mathrm{Ca}^{2+}$ uptake traces after the first $\mathrm{Ca}^{2+}$ addition. D. Quantification of initial mitochondrial $\mathrm{Ca}^{2+}$ uptake rates derived from plots such as shown in panel C. E. Data such as from Panel A were fitted with a first order exponential decay to calculate the minimum $\left[\mathrm{Ca}^{2+}\right]$ achieved in the medium, or the affinity of these mitochondria for $\mathrm{Ca}^{2+}$. ns = non-significant. 
Figure 4. $C R$ alters state 3 mitochondrial oxygen consumption without changes in coupling, membrane potentials $(\Delta \Psi)$ or $\mathrm{H}_{2} \mathrm{O}_{2}$ release in soleus muscle. Mitochondrial oxygen consumption, membrane potentials $(\Delta \Psi)$ and peroxide release were measured as described in the methodology. Blue or red bars and points represent data obtained from AL or CR animals, respectively. A. Oxygen consumption rates were measured in mitochondria incubated, successively, in the presence of succinate and rotenone plus ADP (State 3), oligomycin (State 4) and CCCP (Maximal). B. Respiratory control ratios (State 3/State 4). C. Membrane potentials, calibrated in $\mathrm{mV}$. D. Hydrogen peroxide release, normalized to average $\mathrm{AL}$ fluorescence. $\mathrm{ns}=$ non-significant, ${ }^{* *}$ $p<0.005$ versus $A L$. 

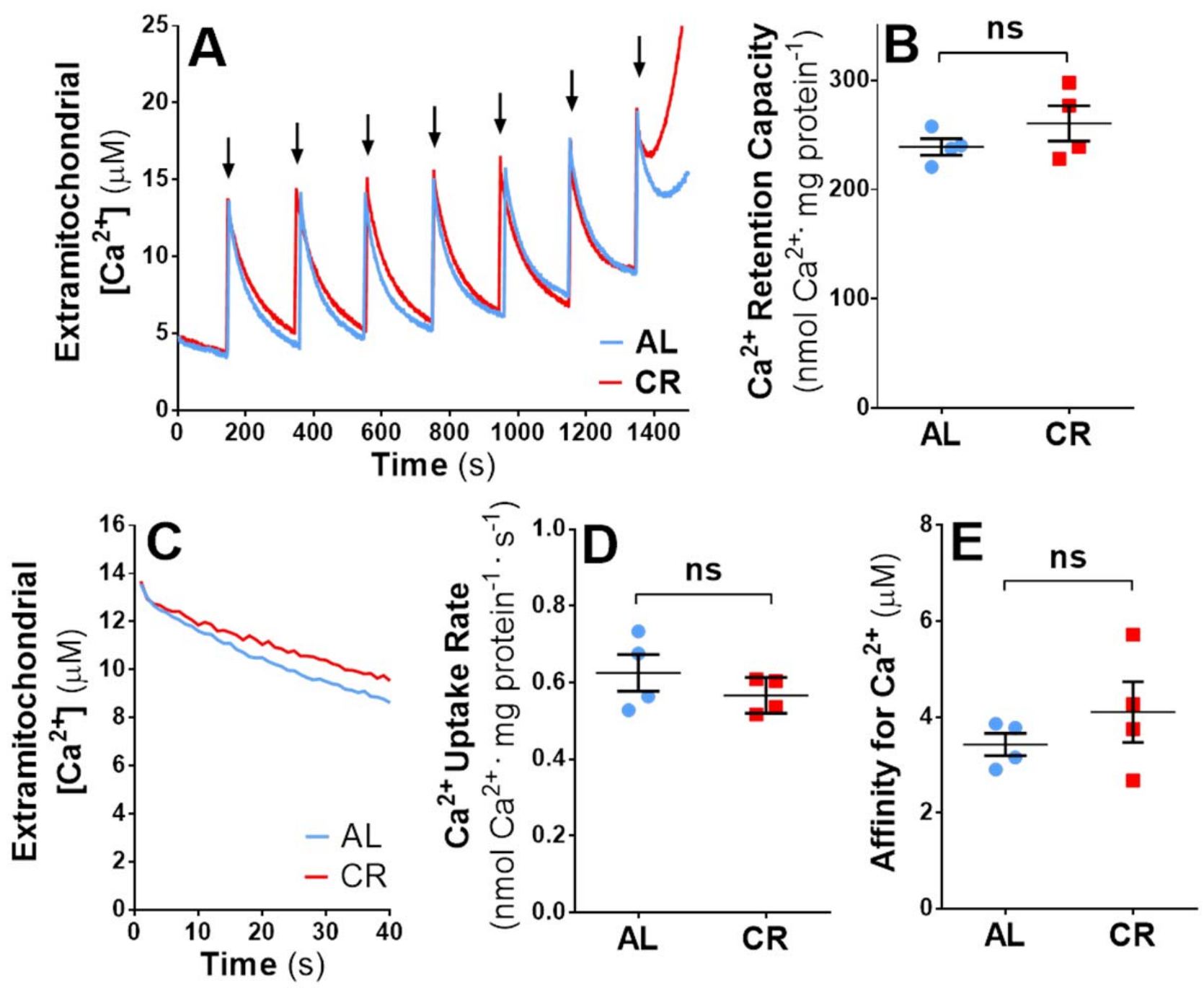

Serna et al., 2020, Fig. 1 

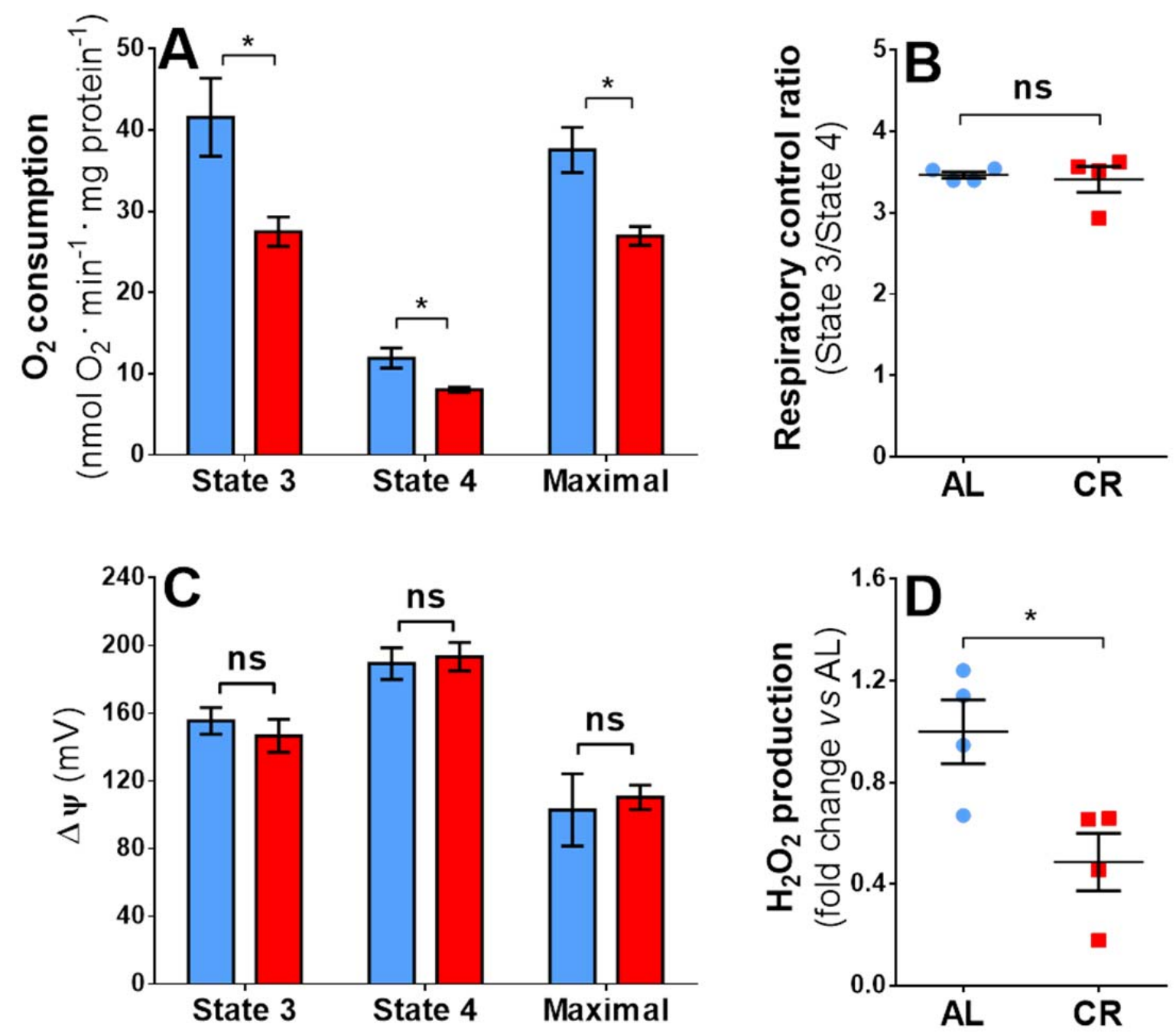

Serna et al., 2020, Fig. 2 

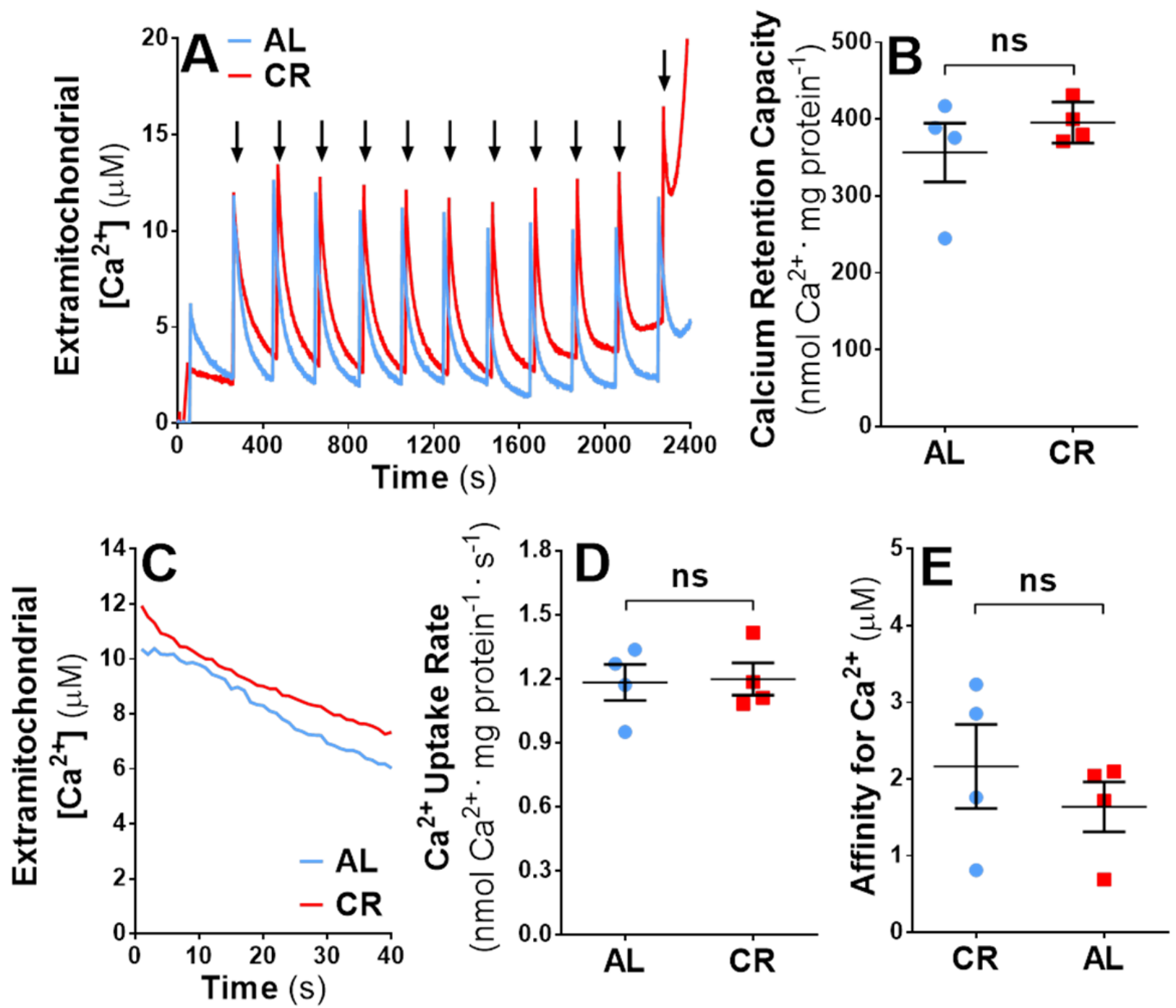

Serna et al., 2020, Fig. 3 

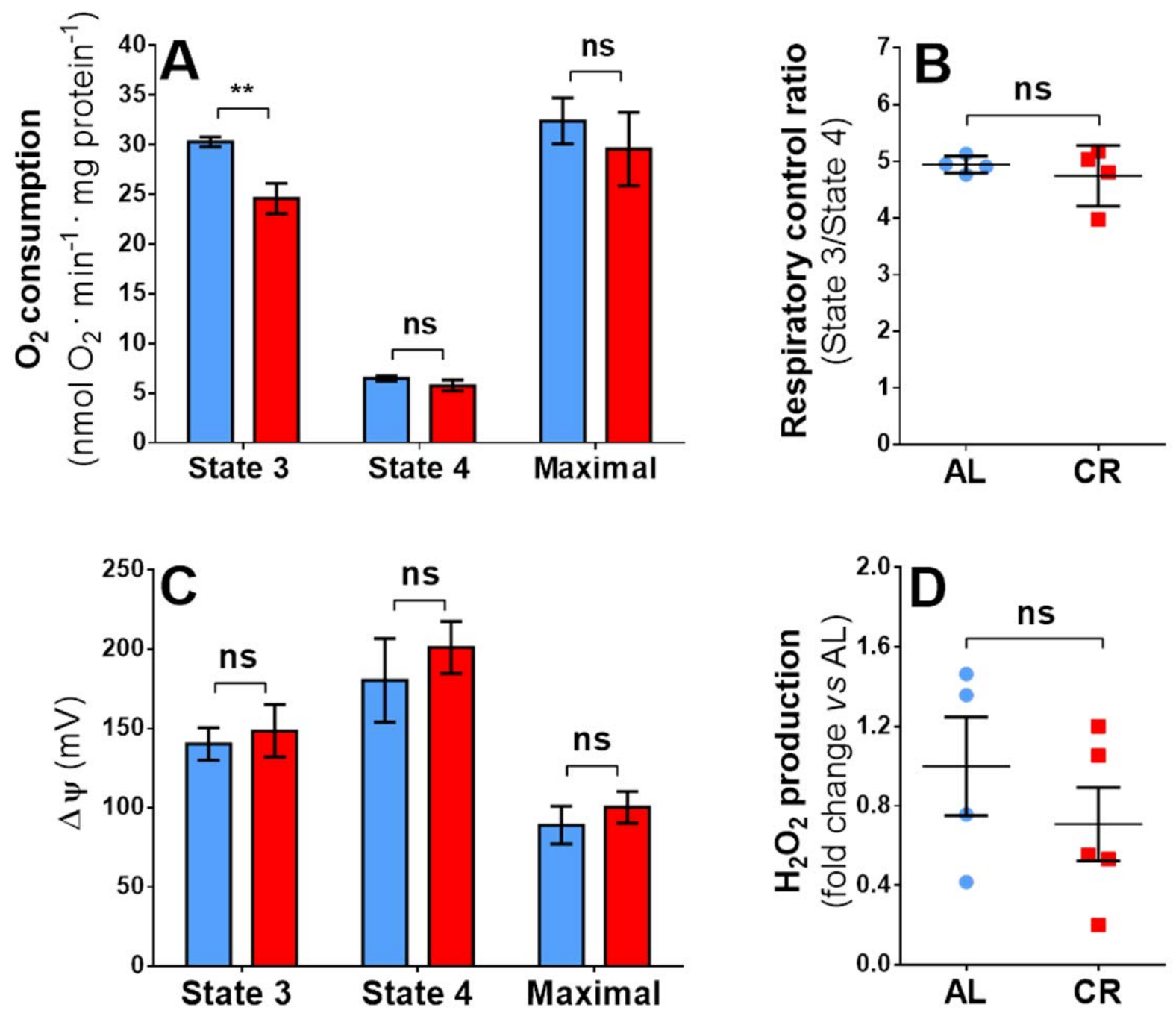

Serna et al., 2020, Fig. 4 